\title{
Fluorescent ADP Sensing in Physiological Conditions based on Cooperative Inhibition of a Miniature Esterase
}

\author{
Laurent Vial and Pascal Dumy* \\ Département de Chimie Moléculaire, UMR-5250, ICMG FR-2607, CNRS - Université Joseph Fourier, BP 53, \\ 38041 Grenoble Cedex 9, France \\ E-mail: pascal.dumy@ujf-grenoble.fr
}

\section{Supporting Information}

\section{Materials and Reagents}

Protected amino acids and ChloroTrityl ${ }^{\mathrm{TM}}$ resin were obtained from Advanced ChemTech Europe and Bachem. All amino acids were of the $L$ configuration. PyBOP was purchased from France Biochem and other reagents from Aldrich, Acros and EMD Biosciences. RP-HPLC experiments were performed on Waters equipment consisting of a Waters 600 controller, a Waters 2487 Dual Absorbance Detector and a Waters In-Line Degasser. The analytical column (Nucleosil $100 \AA 5 \mu \mathrm{m}$ C18 particles, 250 x $4.6 \mathrm{~mm}$ ) was operated at $1 \mathrm{~mL} / \mathrm{min}$ and the preparative column (Delta-Pak ${ }^{\mathrm{TM}} 300 \AA 15 \mu \mathrm{m} \mathrm{C} 18$ particles, $200 \times 25 \mathrm{~mm}$ ) at $22 \mathrm{~mL} / \mathrm{min}$, with UV monitoring at $214 \mathrm{~nm}$ and $250 \mathrm{~nm}$. Solvent A was water containing $0.1 \% \mathrm{TFA}(\mathrm{w} / \mathrm{v})$ and solvent $\mathbf{B}$ was a mixture of acetonitrile/water (90/10) containing 0.1\% TFA (w/v). Mass spectra were obtained by electron spray ionization (ES-MS) on a VG Platform II (Micromass). Fluorescence measurements were carried out with a SpectraMax fluorescence detector. 


\section{Peptide 1 synthesis}

ChloroTritylTM resin $\mathrm{Cl}$

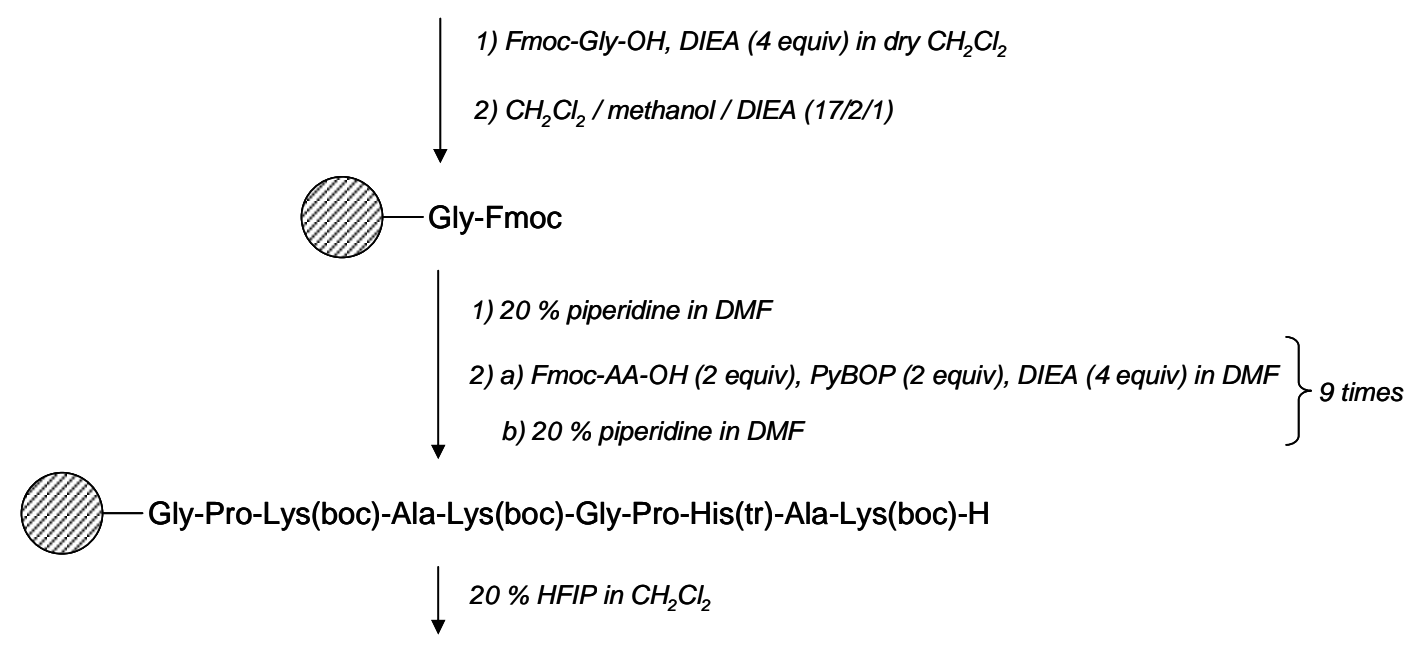

HO-Gly-Pro-Lys(boc)-Ala-Lys(boc)-Gly-Pro-His(tr)-Ala-Lys(boc)-H

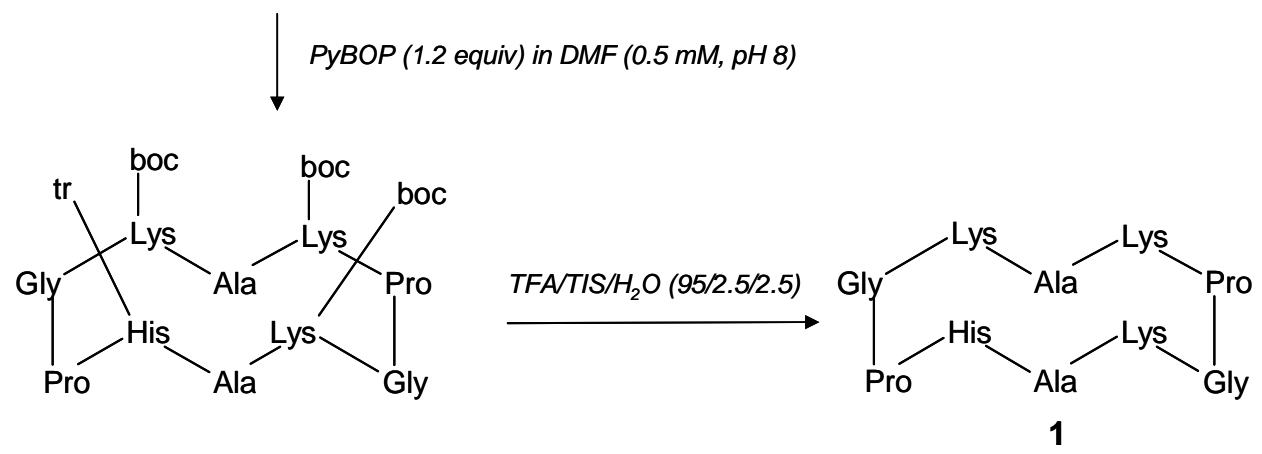

Assembly of the linear protected peptide His-Lys(boc)-Ala-His(tr)-Pro-Gly-Lys(boc)-Ala-Lys(boc)Pro-Gly-OH was carried out manually on ChloroTrityl ${ }^{\mathrm{TM}}$ resin using Fmoc chemistry in a glass reaction vessel fitted with a sintered glass frit. ChloroTrityl ${ }^{\mathrm{TM}}$ resin $(0.500 \mathrm{~g})$ was made to swell in dry dichloromethane $(5 \mathrm{~mL})$. 9-fluorenylmethoxycarbonyl (Fmoc)-Gly-OH $(0.3 \mathrm{mmol})$ was added, followed by diisopropylethylamine (DIEA; 4 equiv). The suspension obtained was shaken for $90 \mathrm{~min}$ at RT. The supernatant was removed by suction and then a dichloromethane/methanol/DIEA (17:2:1) mixture was added to cap the residual chlorotrityl groups on the resin. The loading of the derivatized resin $(0.42 \mathrm{mmol}$ $\mathrm{g} / 1$ ) was determined by Fmoc quantification from UV absorption at $299 \mathrm{~nm}$.

Coupling reactions were performed using 2 equiv of N-Fmoc-protected amino acids activated in situ with 2 equiv of PyBOP and 4 equiv of DIEA in DMF $(10 \mathrm{~mL} / \mathrm{g}$ resin) for $30 \mathrm{~min}$. Couplings completion was controlled by Kaiser and/or TNBS tests. N-Fmoc protecting groups were removed by repeated treatments with piperidine/DMF (1:4) solutions for $10 \mathrm{~min}$. The completeness of deprotection was checked from UV 
absorption of the washings at $299 \mathrm{~nm}$. The linear protected peptide was recovered directly upon acid cleavage with $\mathrm{HFIP} / \mathrm{CH}_{2} \mathrm{Cl}_{2}(4 / 1) .{ }^{1}$ The combined washings were concentrated under reduced pressure, and H-Lys(boc)-Ala-His(tr)-Pro-Gly-Lys(boc)-Ala-Lys(boc)-Pro-Gly-OH was obtained by precipitation from ether.

The previous solid was dissolved in DMF $(0.5 \mathrm{mM})$, and the $\mathrm{pH}$ was adjusted to 8-9 by addition of DIEA. PyBOP (1.2 equiv) was added and the solution was stirred at room temperature for 2-3 h. DMF was evaporated under reduced pressure. The residue was dissolved in water/acetonitrile, and then purified by RPHPLC (elution with $\mathbf{A} / \mathbf{B}(95 / 5)$ to $100 \% \mathbf{B}$ in $30 \mathrm{~min}$, retention time $=12.3 \mathrm{~min}$ ) to afford the cyclic peptide c(-Lys(boc)-Ala-His(tr)-Pro-Gly-Lys(boc)-Ala-Lys(boc)-Pro-Gly-) as a white solid after lyophilization.

Removal of side-chain protecting groups was performed in TFA/TIS/ $\mathrm{H}_{2} \mathrm{O}$ (95:2.5:2.5). After $12 \mathrm{~h}$ of stirring, the solution was evaporated to yield an oily residue, which was precipitated with $\mathrm{CH}_{2} \mathrm{Cl}_{2} / \mathrm{Et}_{2} \mathrm{O}$ to afford pure $\mathbf{1}$ as a tetrahydrotriflate salt ( $143 \mathrm{mg}, 66 \%$ overall yield).

\section{ES-MS (positive mode) spectra of 1}

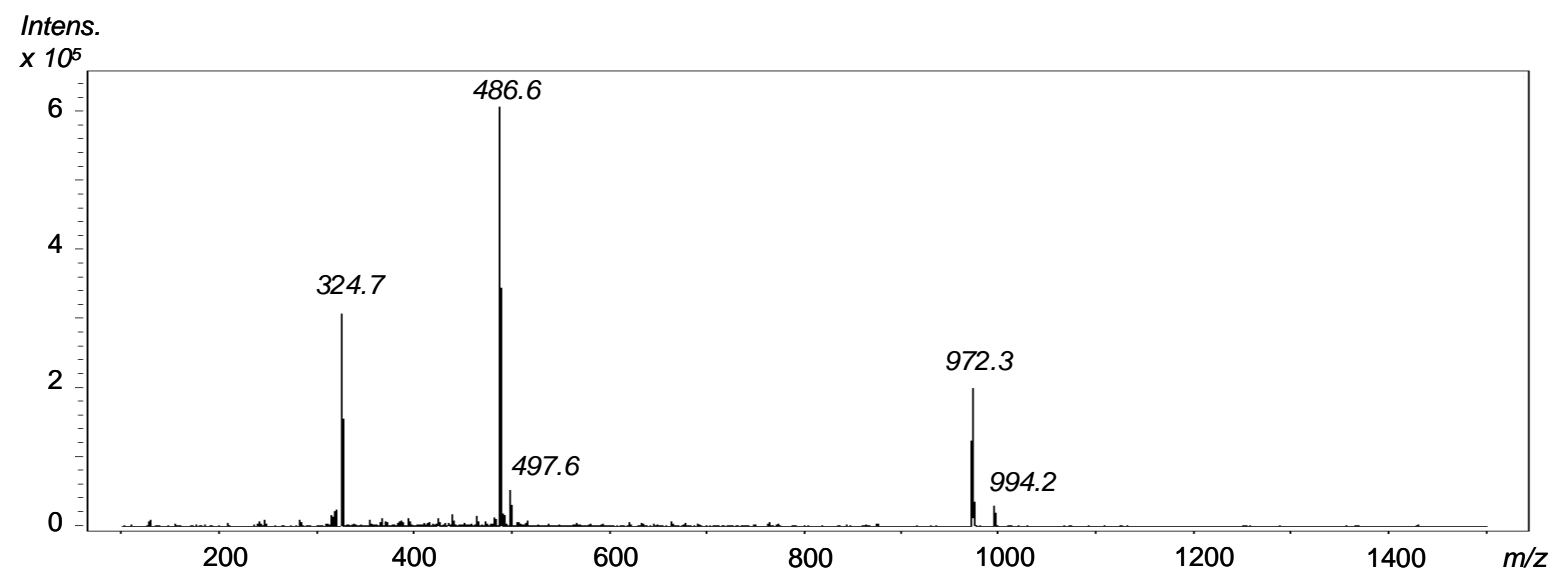

Attribution of the peaks: $m / z=994.2 \rightarrow[\mathrm{M}+\mathrm{Na}]^{+}$

$$
\begin{aligned}
& 972.3 \rightarrow[\mathrm{M}+\mathrm{H}]^{+} \\
& 497.6 \rightarrow[\mathrm{M}+\mathrm{H}+\mathrm{Na}]^{2+} \\
& 486.6 \rightarrow[\mathrm{M}+2 \mathrm{H}]^{2+} \\
& 324.7 \rightarrow[\mathrm{M}+3 \mathrm{H}]^{3+}
\end{aligned}
$$




\section{Kinetic measurements}

The kinetic measurements were carried out by using a SpectraMax fluorescence plate reader $(\lambda \mathrm{ex}=$ $460 \mathrm{~nm}, \lambda \mathrm{em}=530 \mathrm{~nm}$ ) at $24{ }^{\circ} \mathrm{C}$. Assays were followed in individual wells of round-bottom polystyrene $96-$ well-plates. Kinetic experiments were typically followed for 2-12 h. Tris buffer (20 mM, pH 7.4) was freshly prepared using MilliQ deionized water, the $\mathrm{pH}$ being adjusted with aqueous $1 \mathrm{~N} \mathrm{NaOH}$ and aqueous $1 \mathrm{~N}$ $\mathrm{HCl}$ solutions. Initial reaction rates were calculated from the steepest part observed during the first $2000 \mathrm{~s}$ of each curve.

In a typical experiment, $200 \mu \mathrm{L}$ of Tris buffer was first added in a well, then $25 \mu \mathrm{L}$ of a peptide 1 solution (0,05 mM in Tris buffer, final concentration in the well: $5 \mu \mathrm{M})$, and last $25 \mu \mathrm{L}$ of 2 ( $2 \mathrm{mM}$ in water, final concentration in the well: $200 \mu \mathrm{M}$ ). Fluorescence data were converted to product concentration by means of a calibration curve with pure product 3 which was linear in the concentration range used. Michaelis-Menten parameters were obtained from the linear double reciprocal plot of $1 / V\left(V=V_{\text {app }}-V_{\text {uncat }}\right) v s .1 /[2]$ measured with (final concentrations) $5 \mu \mathrm{M}$ peptide 1 or no peptide ( $\left.V_{\text {uncat }}\right)$ and $24,48,64,96,200,400,600$ and 800 $\mu \mathrm{M} 2$ in Tris buffer. The catalytic rate constant $k_{\mathrm{cat}}$ for the hydrolysis is given by $k_{\mathrm{cat}}=V_{\max } /[\mathbf{1}]$.

The reaction rate with 4(5)-methylimidazole (MeIm) was obtained under the same previous conditions with 24, 48, 64, 96, 200, 400, 600 and $800 \mu \mathrm{M}$ MeIm and $200 \mu \mathrm{M} 2$ in Tris buffer. The second order rate constant $k_{\text {MeIm }}$ was calculated from linear regression of the experimentally measured pseudo first order rate constants $k$ ' as a function of MeIm concentrations.

The inhibition constants $K_{\mathrm{I}}$ were obtained from Dixon-plots $1 / V$ versus [inhibitor] measured similarly with $5 \mu \mathrm{M}$ dendrimer, $200 \mu \mathrm{M}$ substrate and $0,24,48,64,96,200,400,60$ and $800 \mu \mathrm{M}$ inhibitor in Tris buffer. Hill coefficient $\left(n_{\mathrm{H}}\right)$ and global dissociation constant $\left(K_{\mathrm{D}}\right)$ were calculated using the Hill equation: $\log$ $\left[V / V_{\mathrm{m}}-V\right]=-n_{\mathrm{H}} \log$ [inhibitor] $+\log K_{\mathrm{D}}$, where $n_{\mathrm{H}}, V_{\mathrm{m}}$ and $K_{\mathrm{D}}$ are the Hill coefficient, the maximum velocity and the global dissociation constant respectively. Each experiment was repeated at least twice.

(1) For information on 1,1,1,3,3,3-hexafluoro-2-propanol (HFIP)-mediated cleavage from 2-chloro-trityl chloride resins, see: Bollhagen, R.; Schmiedberger, M.; Barlos, K.; Grell, E. J. Chem. Soc., Chem. Commun. 1994, 25592560 . 